\title{
Interactive comment on "Electrical Formation Factor of Clean Sand from Laboratory Measurements and Digital Rock Physics" by Mohammed Ali Garba et al.
}

\section{Anonymous Referee \#5}

Received and published: 13 April 2019

The manuscript is about measuring and numerically computing formation factor of sand-pack samples. The problem is well known and the author did not improved it theoretically, but conducting such neat experiments and computations are interesting. The MS is well written with fluent English and proper structure, which a reader can easily follow it from A to $Z$. In overall, I think it deserves to be published after some corrections. My main concern is: Discussion is mostly a report than a really discussion. There are at least two questionable points, which should be considered in this part: i. difference between FF of rectangular and cylindrical cells, and ii. different trends between FF and porosity in Figure 9. For example, there are obviously another trends than FF=Phi^(-m) in some cases (e.g., Scarborough Beach, flow or Cottesloe 
Beach, static), but authors insisted on Archie trend. These differences go back to the porous structure of each sample and since the authors have access to it (I mean via segmented images), they should do more extensive work in this part. They can at least calculate pore network model or tortuosity of flow paths of each sample and compare their properties to find reasonable relationships.

Interactive comment on Solid Earth Discuss., https://doi.org/10.5194/se-2018-133, 2019. 